Research Article

\title{
Research on a Self-Coupling PID Control Strategy for a ZVS Phase-Shift Full-Bridge Converter
}

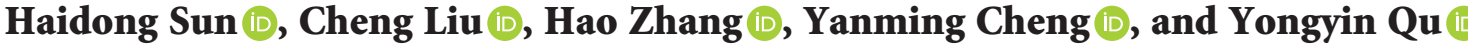 \\ College of Electrical and Information Engineering, Beihua University, Jilin, China \\ Correspondence should be addressed to Cheng Liu; liucheng@beihua.edu.cn
}

Received 15 December 2020; Revised 8 February 2021; Accepted 24 February 2021; Published 9 March 2021

Academic Editor: Junyong Zhai

Copyright (C) 2021 Haidong Sun et al. This is an open access article distributed under the Creative Commons Attribution License, which permits unrestricted use, distribution, and reproduction in any medium, provided the original work is properly cited.

\begin{abstract}
As an important part of the high-frequency switching power supply, the control accuracy of the phase-shift full-bridge converter directly affects the efficiency of the switching power supply. To improve the stability and antidisturbance ability of phase-shift control systems, this article presents a dual closed-loop control system based on Self-Coupling PID (SC-PID) control and applies the SC-PID control strategy to the voltage control of the phase-shift full-bridge converter. To begin with, in response to the contradiction of traditional PID, SC-PID breaks the limitation of PID control by introducing a new control idea instead of weighted summation of each gain, which fundamentally solves the contradiction between overshoot and rapidity. Then, using the dimension attributes between gains to develop new tuning rules to solve the system load disturbance, output voltage deviation from the reference value, and other problems, the purpose is to ensure the stability of the output voltage and improve the control effect. At the same time, the stability of the whole control system is analyzed in the complex frequency domain. Finally, with the same main circuit and parameters, three types of controllers are built separately, and using MATLAB for simulation comparison, the simulation results show that the control system based on SC-PID has better steady-state accuracy, faster response, and better robustness, which proves the feasibility of the SC-PID control idea.
\end{abstract}

\section{Introduction}

The phase-shift full-bridge converter has the advantages of low output voltage ripple level and high power efficiency [1], it is widely used in high-frequency switching power supply, with the improvement of the phase-shift full-bridge converter's performance requirements, and more and more new control techniques are being applied to the control loops of the phase-shift full-bridge converter. [2]. The phase-shift full-bridge converter is a necessary part of the switching power supply, its working condition directly affects the efficiency of the switching power supply, and with the increasing requirements of enterprises for switching power supply, switching power supply in high service life, the internal components are prone to lose their original properties, which may lead to deviation of the power supply output voltage or more serious consequences; to cope with the possible problems, we design a phase-shift full-bridge converter that is insensitive to changes in internal and external parameters and has simple structure and strong application type.

At present, an extensive number of control algorithms have been connected to the control field for the phase-shift full-bridge converter; the traditional PID controller and other control theories joined to produce some new PID controllers. For example, the fuzzy PID control proposed in $[3,4]$ has good robustness to the perturbation of system parameters, can adapt to the time-varying nonlinear phaseshifted full-bridge, and makes up for the deficiency of the traditional PID controller, but the membership function and control rules of fuzzy control are usually selected by experience, and it is troublesome to obtain a satisfactory control effect. The PID control strategy based on the BP neural network proposed in [5] enhances the control correctness without relying on the mathematical model. Despite that the control strategy may be additionally steady for the control framework of the phase-shifted full-bridge proportion converter over the fuzzy PID control, it is easy to fall 
into the local search for the optimal PI value, and not from a global view in-depth study. With further research, some modern algorithms are also applied to the control. The PI control strategy optimized by the genetic algorithm proposed in $[6,7]$ can not only optimize the parameters but also track the changes of the system parameters, modify the parameters accordingly, and maintain the good performance of the system in a bad environment. The PSO-SA hybrid optimization algorithm presented in $[8,9]$ combines the advantages of the two single algorithms and achieves a good control effect. But, this kind of control has a common disadvantage, which is that the control system is stabilized by optimizing a PID gain value through an intelligent algorithm, although the contradiction between the rapidity and overshoot of the PID control system is solved to some extent; however, the reason for the poor robustness of the PID gain is not that the parameters of the gain are not accurate enough. Rather, the PID is a weighted sum of three parameters with different physical properties, proportional, integral, and differential, resulting in this phenomenon, which does not conform to the basic rules of arithmetic operations. Besides, there is another kind of control strategy that does not rely on the PID controller. For example, a three-phase phase-shift (TPS) control strategy is proposed for the full-bridge three-level (FBTL) DC/DC converter [10], a dual phase-shift control method widely used in the DC-DC converter [11,12], and active disturbance rejection control (ADRC) technology which has been applied to the field of switching power supply $[13,14]$. The ADRC control strategy is similar to the control strategy used in this paper. It can control the converter without changing the topology and driving pulse. Although ADRC does not rely on tuning PID gain to optimize the system, there are also some problems in ADRC, such as the nonlinear function in nonlinear error feedback control (NLSEF) is not smooth, it is easy to cause chattering, and the error compensation performance is poor under sudden external interference $[15,16]$.

Without changing the topology of the main circuit, the new controller composed of the abovementioned intelligent algorithm and PID control achieves different control effects; however, when the external disturbance or internal parameters change, as a large amount of calculation of various algorithms and their optimization of PID gain parameters cannot reach a global optimal value, the output parameters of the converter may produce large errors, which makes the controller have some limitations in real-time control. Reference [17] analyses the physical attribute of the PID control system and reveals the two contradictions through analysis: the dimension conflict and the uncoordinated control mechanism; according to these two contradictions, the potential basic theoretical problems of the PID control rate are proved, and the controlling idea of Self-Coupling PID (SC-PID) is designed [18]. SC-PID designed the SC-PID control law with the speed factor as the core coupling factor by analyzing the dimension conflict, converting three physical quantities with different properties into the same property by introducing the speed factor, and achieving the purpose of cooperative control by controlling the speed factor, which fundamentally solves the problem of poor robustness of the PID control system. Without depending on the mathematical model of the controlled object, SC-PID has the advantages of the simple control structure, insensitivity to system parameter variations, and external disturbances, and theoretical analysis shows that the closedloop control system constituted by it has good global stability and robustness.

The main contribution of this paper is the first application of the SC-PID control strategy to a phase-shifted fullbridge double closed-loop control system, and the designed system is modeled and simulated with the same main circuit topology, parameters, and external disturbances, by comparing the control effects of PID, LADRC, and SC-PID controllers, the feasibility of the SC-PID control idea is proved, and the effectiveness, rapidity, stability, robustness, and antijamming of the control strategy are verified by simulation.

\section{Materials and Methods}

2.1. Main Topology Structure and the Working Principle. Since the switching frequency of high power switching power supply is generally designed in $40-100 \mathrm{kHz}$ and the hard switch will produce a large switching loss in high frequency, based on this, this article uses a phase-shift fullbridge ZVS circuit to reduce the loss and improve the life of the switch tube. Figure 1 shows the phase-shift ZVS circuit diagram.

In Figure 1, $T$ is an isolated transformer, $Q_{1}, Q_{3}$ are leading legs, $Q_{2}, Q_{4}$ are lagging legs, and $L_{r}$ is the leakage inductance of the high-frequency transformer and the main resonant inductance. The secondary side of the transformer adopts a full-bridge rectifier to transform the low-voltage AC square wave into low-voltage DC.

Phase-shifting control generates AC square wave voltage by controlling the cooperative control of a leading bridge arm and a lagging bridge arm, controls the output voltage by controlling the phase-shift angle of the cooperative bridge arm, and ZVS of the switch tube is realized by the resonant inductance and capacitor resonance in parallel at both ends of the switch tube [19].

2.2. Control System Design. Considering that the phase-shift full-bridge converter studied in this paper has high requirements on the dynamic and steady-state performance of the system and the working characteristics of the load, we choose the double closed-loop control system with a current inner loop and voltage outer loop. As the traditional double closed-loop PI control cannot solve the contradiction between overshoot and rapidity, this paper improves the voltage outer loop by replacing the traditional PI with the Self-Coupling PI (SC-PI) control. The working principle block diagram of the phase-shift full-bridge converter is shown in Figure 2.

Ignoring the role of high-frequency transformers, the amplitude of AC voltage is equal to that of output voltage, which is both high-frequency pulse voltage, and the amplitude of input current is equal to that of the output 


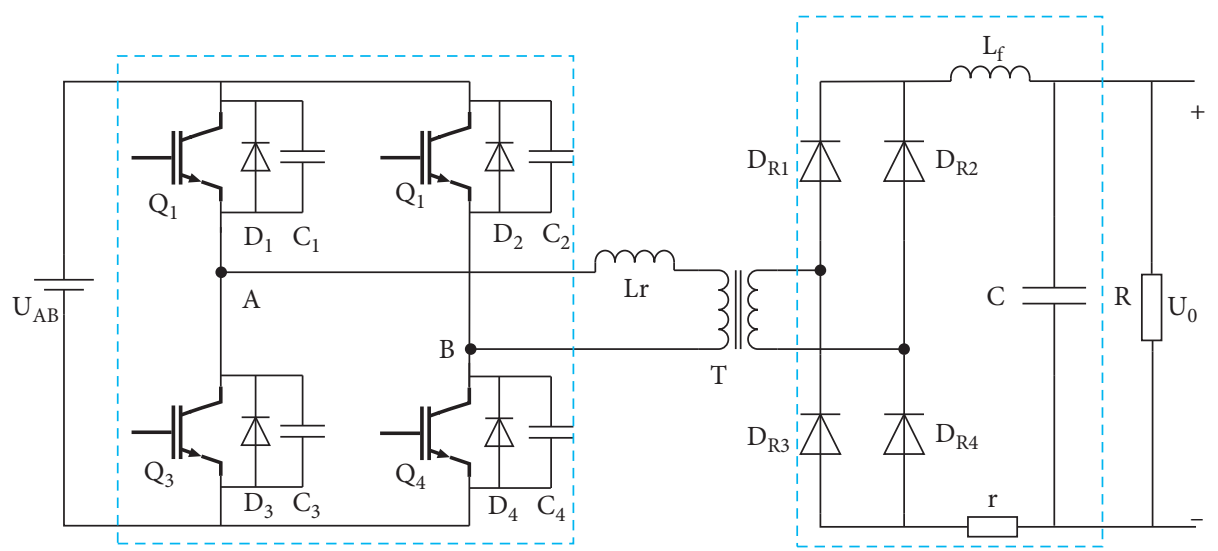

Figure 1: Phase-shift full-bridge circuit topology.

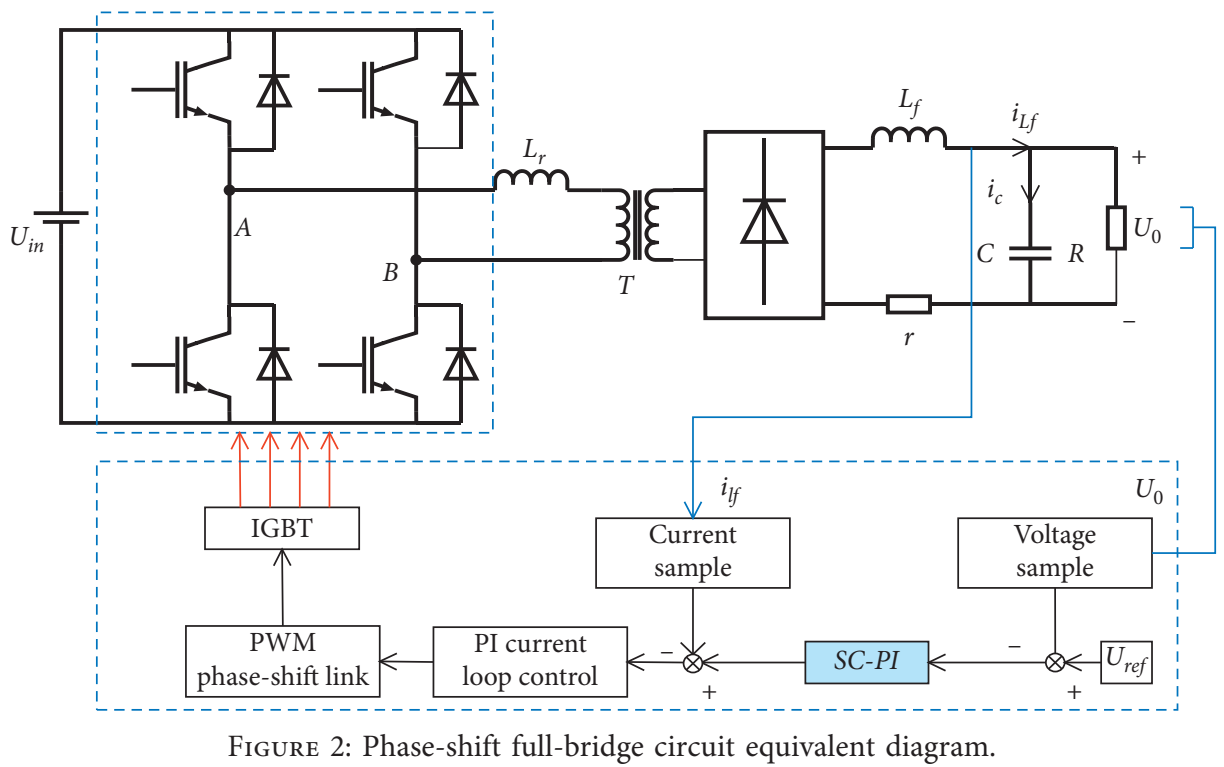

inductor current; therefore, the output voltage and current can be satisfied by controlling the effective time per unit cycle. The mathematical model of the full-bridge switching power supply is

$$
\left\{\begin{array}{l}
U_{A B}=L_{f} \frac{\mathrm{d} i_{l f}}{\mathrm{~d} t}+r i_{l f}+U_{0}, \\
i_{l f}=C_{0} \frac{\mathrm{d} U_{0}}{\mathrm{~d} t}+i_{0} .
\end{array}\right.
$$

After Laplace transformation,

$$
\left\{\begin{array}{l}
U_{0}=\frac{i_{l f}-i_{0}}{C_{0} s}, \\
i_{l f}=\frac{U_{A B}-i_{0}}{L s+r} .
\end{array}\right.
$$

2.2.1. Current Inner-Loop PI Control. According to the control requirements of the phase-shift full-bridge converter, the control system is expected to have fast current tracking performance, so the current loop is designed according to the typical type I system. According to the mathematical model of equation (2), the control block diagram of the current inner-loop system is established, where $r$ is the comprehensive damping resistance, as shown in Figure 3.

Its open-loop transfer function is

$$
G_{i}(s)=\frac{K_{p} K_{p w m}\left(\tau_{i}+1\right)}{\tau_{i} s\left(T_{s} s+1\right)(L s+r)},
$$

where $K_{p i}$ is the current loop proportional coefficient, $T_{s}$ is the system clock cycle, and $\tau_{i}$ is the sampling period.

From the typical type I system tuning rules obtained,

$$
\left\{\begin{array}{l}
K_{p}=\frac{r^{2} T_{s}}{4 \varepsilon^{2} L K_{p w m}}, \\
K_{i}=\frac{K_{p}}{\tau_{i}} .
\end{array}\right.
$$




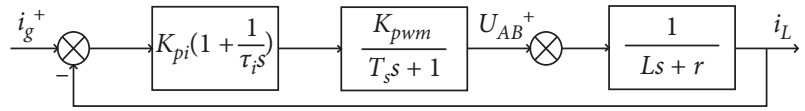

FIgURE 3: Transfer function diagram of the inner current loop.

2.2.2. Voltage Outer-Loop SC-PI Control. In this paper, a new control system named SC-PID is applied to the voltage outer loop. Classical PID parameters' combination can form three kinds of controllers; SC-PID also has three corresponding controllers: SC-PI, SC-PID, and SC-PD. In this paper, SC-PI can meet the requirements of accurate and stable operation; the following is a brief introduction to its design and working principle. As shown in Figure 4, the flow chart of establishing an SC-PI controller is shown.

The mathematical model of the first-order nonlinear uncertain system is as follows:

$$
\left\{\begin{array}{l}
\dot{x}=f(x, u)+d_{1} \\
y=x
\end{array}\right.
$$

Among them, $x \in R$ is a measurable state, $u \in R$ Is the control input, $y \in R$ is the system output, $f(x, u)$ is an unknown uncertain function, and $d_{1}$ is the unknown external bounded disturbance.

The total disturbance for the nonlinear uncertain system is defined as

$$
d=f(x, u)+d_{1}-b_{0} u
$$

In the abovementioned formula, $b_{0} \neq 0$ is the estimated model gain of the controlled system.

Thus, system (5) can be rewritten as a class of first-order linear uncertain systems:

$$
\left\{\begin{array}{l}
\dot{x}=d+b_{0} u \\
y=x
\end{array}\right.
$$

Systems (7) and (5) are equivalent [20]. System (5) is transformed into a linear uncertain system (7) by defining the system dynamic and external disturbances as total disturbances, then the error dynamic system is obtained through the system, and the compensation controller is established for system (7).

SC-PI controller design based on system (7).

The tracking error is defined as

$$
e_{1}=r-y
$$

where $r$ is the expected output of the system, and the integral of error is

$$
e_{0}=\int e_{1} \mathrm{~d} \tau
$$

Combined with system $\mathrm{fd} 7(7)$,

$$
\dot{e}_{1}=\dot{r}_{1}-\dot{y}=\dot{r}-d-b_{0} u
$$

The error dynamic system can be obtained as follows:

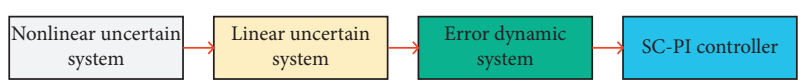

FIGURE 4: Flow chart of controller establishment.

$$
\left\{\begin{array}{l}
\dot{e}_{0}=e_{1} \\
\dot{e}_{1}=\dot{r}-d-b_{0} u
\end{array}\right.
$$

To make the system gradually approach $e=0$ from the nonzero initial state $e \neq 0$, the SC-PI controller model is designed according to the design idea in [18] as follows:

$$
u=\frac{\left(\dot{r}+z_{c}^{2} e_{0}+2 z_{c} e_{1}\right)}{b_{0}} \text {. }
$$

$Z_{C}>0$ is the speed factor of the SC-PI controller, which is the most important parameter of this controller.

The closed-loop control system based on the controller model is shown in Figure 5.

Compared with the traditional PI controller, the main innovation of the SC-PI controller is that there is only one speed factor $Z_{C}$ and the setting rules of the SC-PI controller is only related to the speed factor and have nothing to do with the specific model of the controlled object. SC-PI has a better control effect on the nonlinear system, and its main feature is through the coupling effect of $Z_{C}$; its main feature is coupling two physical links with different properties, proportional and integral, together to form a synergistic control signal, so the gain setting rules of SC-PI are equivalent to $K_{P}=2 Z_{C}, K_{i}=Z_{C}^{2}$.

2.3. Stability Analysis and Adaptive Speed Factor of Control System. The mathematical model of the controller is brought into the error dynamic system of the controlled second-order system to obtain

$$
\left\{\begin{array}{l}
\dot{e}_{0}=e_{1}, \\
\dot{e}_{1}=e_{2} \\
\dot{e}_{2}=-d-z_{c}^{2} e_{0}+2 z_{c} e_{1} .
\end{array}\right.
$$

Formula (13) is a closed-loop control system under the reverse excitation of total disturbance, due to the initial state $\dot{\mathrm{e}}_{0}=0, \dot{\mathrm{e}}_{0} \neq 0$. Formula (13) is obtained by unilateral Laplace transform:

$$
\left\{\begin{array}{l}
S E_{0(s)}=E_{1(s)}, \\
S E_{1(s)}=E_{2(s)}+\dot{e}_{1}, \\
S E_{2(s)}=-D_{(s)}-Z_{c}^{2} E_{0(s)}-2 Z_{c} E_{1(s)}+\dot{e}_{2} .
\end{array}\right.
$$

The transfer function of the closed-loop control system is

$$
H_{(S)}=\frac{E_{1(S)}}{D_{(S)}}=-\frac{1}{\left(s^{3}+2 Z_{c} s+Z_{c}^{2}\right)^{2}} .
$$

From the complex frequency domain analysis, we know that, in the case of $Z_{C}>0$, all the identical poles of the control system are in the left half-plane of the $s$-axis, so the closed-loop control system fd15(15) is globally asymptotically stable. Moreover, the stability of the controller is only 




FIGURE 5: Closed-loop control system model based on SC-PI.

related to the speed factor, independent of the controlled object model, and the system has good robustness [21], no proof here.

To improve the response speed of the system, $Z_{C}$ should be large as far as possible; however, when $Z_{C}$ is too large, the gain of the integrator will be too large, resulting in a large overshoot. Therefore, to avoid overshoot and oscillation caused by integral saturation while ensuring fast response speed and strong antidisturbance ability, an adaptive speed factor model is proposed:

$$
Z_{C}=\frac{\alpha}{T_{r}}\left[1-0.9 e^{(-\beta t)}\right]
$$

where $0<\alpha<100, \beta=\left(1 / T_{r}\right), T_{r}$ is the adjustment time of the controlled system from dynamic to steady-state, and it is usually necessary to build a specific simulation model for measurement; for the system with fast dynamic response speed, it is usually arbitrary in the range of $10<\alpha<100$; the larger the value of $\alpha$ is, the faster the response speed is and the stronger the antidisturbance ability is.

The adaptive speed factor designed by this method effectively solves the phenomenon of overshoot, and its value increases as time goes by, but there is a maximum.

\section{Results and Discussion}

To verify the practicality of the Self-Coupling PID, the proposed control strategy in this paper is verified by simulation. The main technical parameters are as follows: input voltage: $U_{\text {in }}=500 \mathrm{~V}$; output voltage: $U_{0}=5 \mathrm{~V}$; output current: $I_{0}=1000 \mathrm{~A}$; switching frequency: $F_{S}=10 \mathrm{kHz}$. In the simulation, because of the existence of the differential, we give the input a transition process: $U_{\text {ref }}=5-e^{-50 t}$.

Two other controllers with proven applications, PID and LADRC controllers, are also designed and used to compare and analyze the feasibility of the control method used in this paper. The relevant parameters of the PID controller and the LADRC controller are represented in Tables 1 and 2, respectively.

Figure 6(a) shows the output voltage waveform when the adaptive speed factor is $\alpha=100$, and due to the relationship between the expected output voltage and the current, the initial load resistance is $R=0.005 \Omega$; in order to verify its antidisturbance ability, $10 \%$ load disturbance is added when the output is stable, A load resistor with $R=0.045 \Omega$ is connected in parallel at $0.15 \mathrm{~s}$, changing the resistance to $90 \%$ of the original, and the waveform graph shows that the output voltage returns to the desired voltage $U_{0}=5 \mathrm{~V}$ near
Table 1: Traditional PID control system.

\begin{tabular}{lccc}
\hline PID controller & $\mathrm{Kp}$ & $\mathrm{Ki}$ & $\mathrm{Kd}$ \\
\hline Voltage outer loop & 2.86 & 9193.8 & 0 \\
Current inner loop & 0.0649 & 59 & 0 \\
\hline
\end{tabular}

TABLE 2: LADRC control system.

\begin{tabular}{lcccc}
\hline LADRC controller & $\mathrm{Kp}$ & $\mathrm{Ki}$ & $\mathrm{Kd}$ & $\mathrm{b} 0$ \\
\hline Voltage outer loop & 5198 & 0 & 100 & 630 \\
Current inner loop & 0.0649 & 59 & 0 & 0 \\
\hline
\end{tabular}

$0.2 \mathrm{~s}$. The perturbation is rounded off at $0.3 \mathrm{~s}$, and the resistance becomes large, resulting in a drop in the current at the output, and then, the voltage and current are quickly and smoothly regulated to the desired value by the controller's regulating action. We can see from the waveform that the output voltage can be quickly adjusted to the desired voltage within the allowable range of load disturbances, whether the load is added or reduced. Compared with [22], the converter designed with model predictive control optimized by intelligent algorithm, with or without load perturbation, has lower output voltage accuracy and it can be clearly seen that the output voltage consists of a larger ripple.

Besides, the adjustment margin of the system is set to $\alpha=10,30,50,70,100$ under the same parameters, as shown in Figure 6(b); under the same condition that the adaptive speed factor is 10 times different, the simulation waveform can reach $5 \mathrm{~V}$ without overshoot, and when $\alpha=110$, it starts to overshoot. It indicates that the control in this paper has a strong antidisturbance ability and global asymptotic stability. The design of the adaptive speed factor and the reasonable regulation of the input tracking transition process have had a certain effect on the overshoot suppression.

As perceived from Figure 7, the control method has high steady-state control accuracy and smaller pulsation of the output voltage. It can be seen that, after $0.25 \mathrm{~s}$, the accuracy of the tracking error does not exceed 0.0225 in the case of adding \pm 10 amplitude triangular wave disturbance to the control output, and the steady-state accuracy does not exceed 0.006 without disturbance. In comparison with [23], which uses sliding-mode control in the control link of a phase-shifted full-bridge converter, the output voltage error reaches a maximum of $2 \mathrm{~V}$ with perturbations applied to the control output.

Since the control mechanism of SC-PI and ADRC is very similar, simulation comparison is carried out under the same 


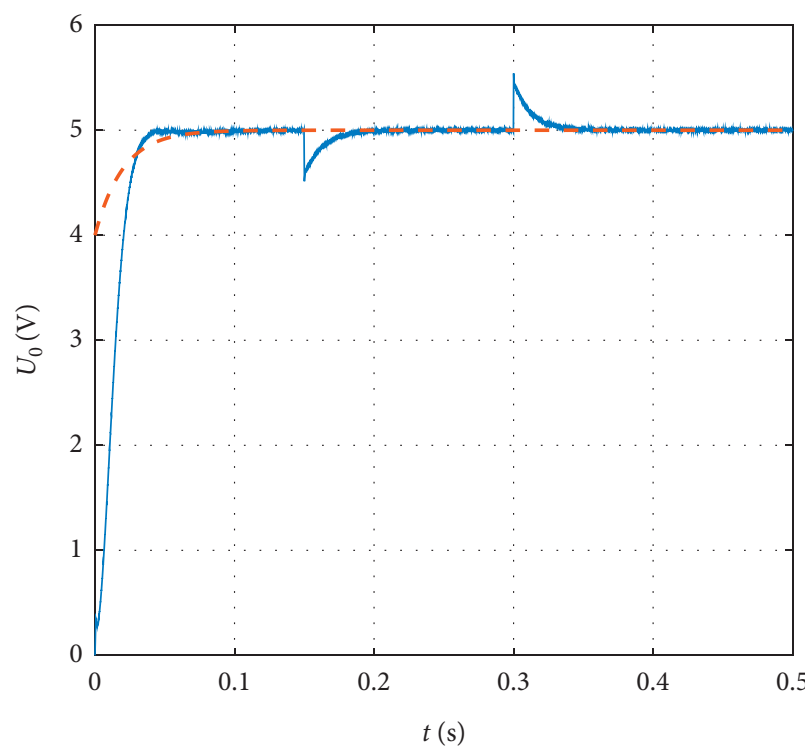

- SC-PI - - $U_{\text {ref }}$

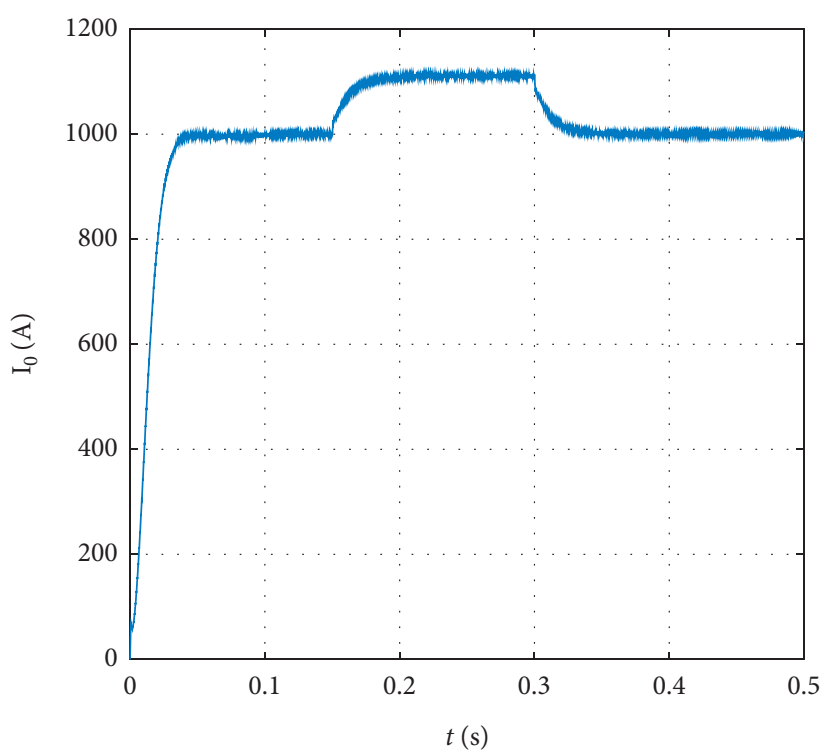

$-\mathrm{I}_{0}$

(a)

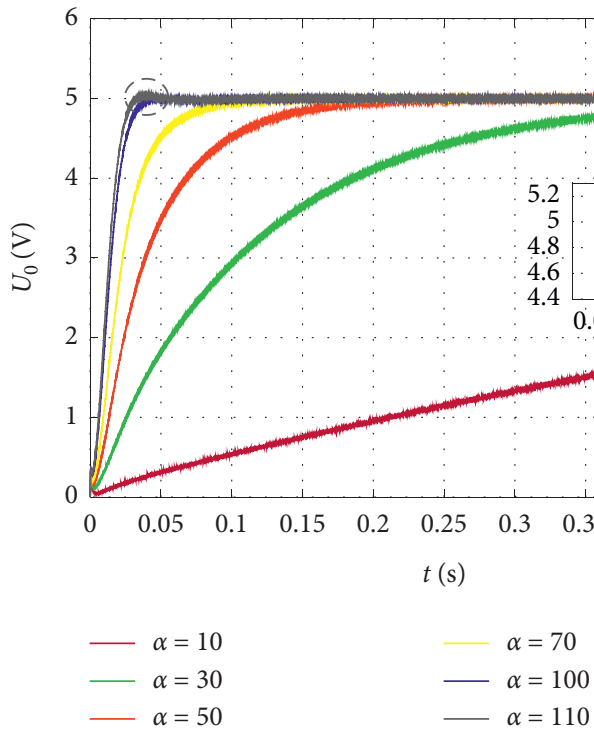

(b)

Figure 6: Output voltage. (a) Output voltage waveform. (b) Output voltage waveform at different $\alpha$.

conditions. To avoid high-frequency oscillation of capacitor voltage caused by the tracking differentiator, this paper uses LADRC for comparative simulation. Both controls add load perturbation at 0.25 in the case of the same main circuit topology. The simulation results are shown in Figure 8, The results show that the reaction speed of SC-PI is faster than that of LADRC, SC-PI is easier to adjust than LADRC, often only needed to adjust $\alpha$ and the controlled object gain $b_{0}$ to make the system stable, LADRC has many parameters to adjust, and the real-time performance is relatively poor. 


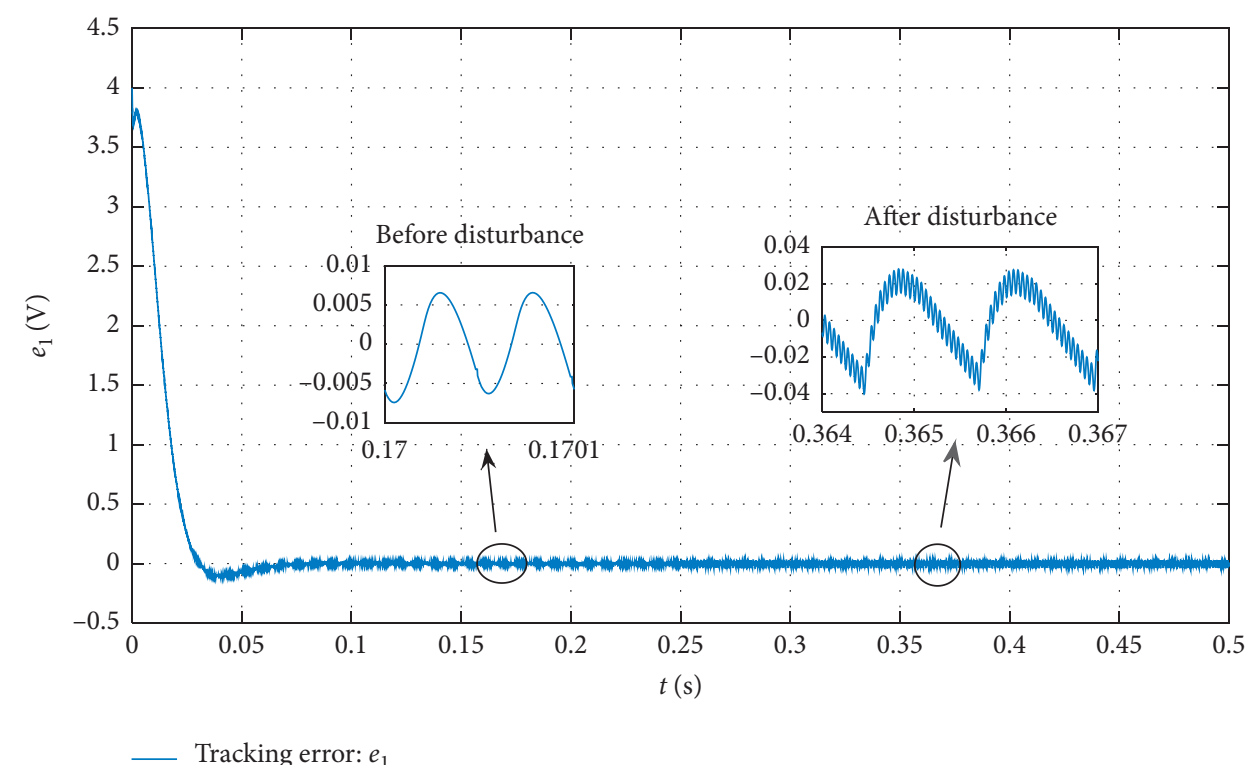

FIgURE 7: Tracking error.

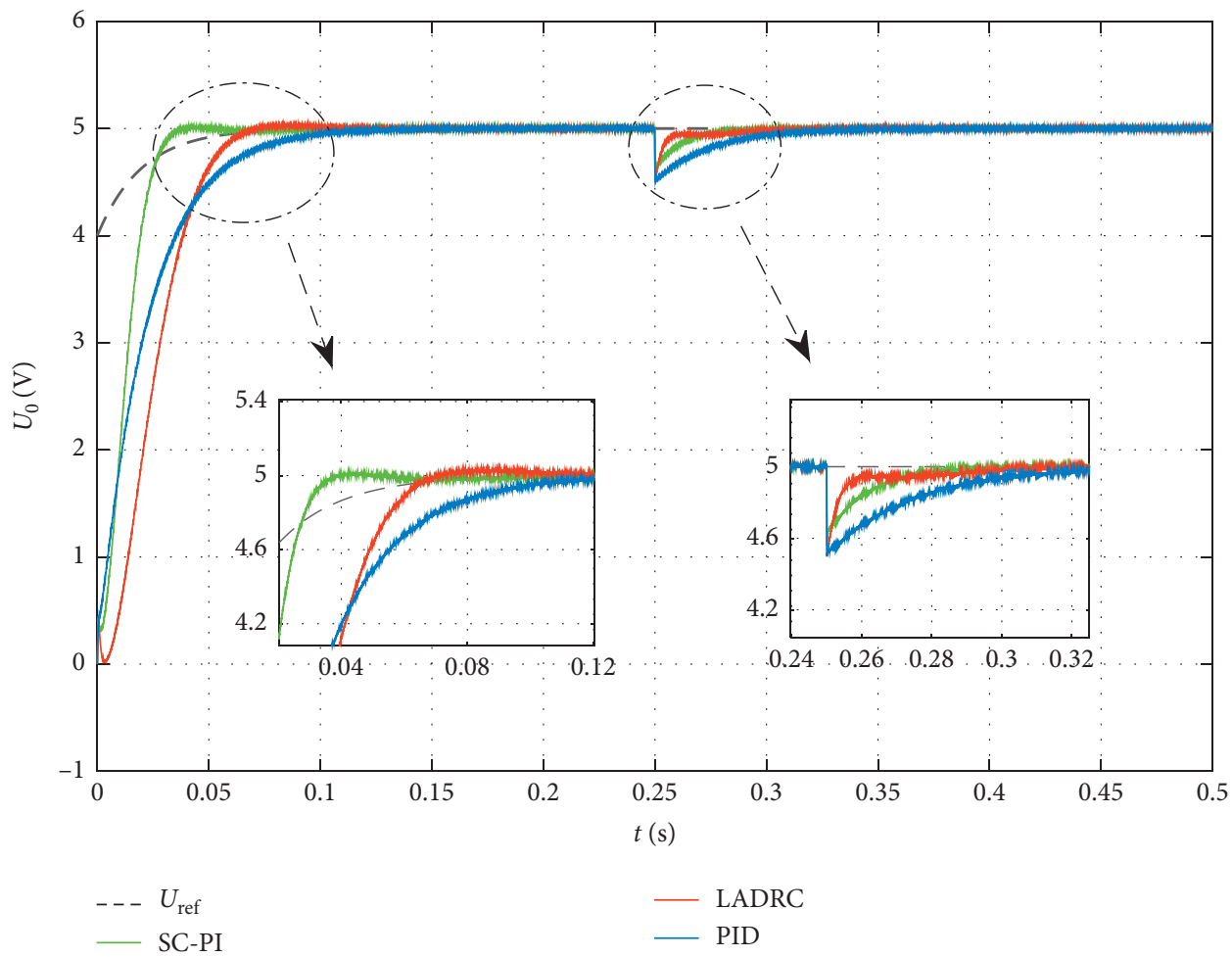

Figure 8: Output voltage.

\section{Conclusions}

In this paper, introduction of SC-PI control technology into a dual closed-loop control system for the steady-state accuracy and disturbance performance of phase-shifted fullbridge is shown. For the full-bridge converter and nonlinear system, LADRC improves the control accuracy and antidisturbance performance by using the extended state observer (ESO) to observe the internal and external disturbances of the system and then compensate it by nonlinear error feedback control; however, due to the lack of a tracking differentiator (TD), the contradiction between overshoot and rapidity cannot be optimally controlled. SCPI couples the error and the integration of error by introducing the speed factor and adjusts the controller to the optimal control state by changing the coupling coefficient. The SC-PI control method eliminates the ESO and makes the controller structure more simple and better in real-time. The 
simulation comparison of LADRC and SC-PI shows that the control system with SC-PI as the closed-loop control has faster response speed and better antidisturbance and robustness, and confirmed the feasibility of the SC-PID control idea, laying the foundation for the development of SC-PID controllers in the field of aviation and industrial control; SCPID has important theoretical significance and wide application prospects in the field of control of unknown nonlinear complex systems.

Although, SC-PID determines the internal connection of each gain of traditional PID through the principle of dimension attributes and formulates its own tuning rules by introducing speed factor. However, the internal relationship between the gain of the traditional PID is only a qualitative relationship in accordance with the dimensional attributes, and for the exact relationship between the gain, we need to do further research.

\section{Data Availability}

The data used to support the findings of this study are available from the corresponding author upon request.

\section{Conflicts of Interest}

The authors declare that there are no conflicts of interest regarding the publication of this paper.

\section{Acknowledgments}

This research was supported by the Project of Science and Technology Department of Jilin Province: High power electronic technology and parallel robot technology innovation team of Jilin province $(20190101018 \mathrm{JH})$ and the Project of Science and Technology Department of Jilin Province: Research on key technology of high efficiency and high power phase-shifted full-bridge soft switching electrolytic power supply(JJKH20200044KJ).

\section{References}

[1] K. Shi, D. Zhang, Z. Zhou, M. Zhang, and Y. Gu, "A novel phase-shift dual full-bridge converter with full soft-switching range and wide conversion range," IEEE Transactions on Power Electronics, vol. 31, no. 11, pp. 7747-7760, 2016.

[2] M. Yu, D. Sha, and X. Liao, "Hybrid phase shifted full bridge and LLC half bridge DC-DC converter for low-voltage and high-current output applications," in IET Power Electronicsvol. 7, no. 7, pp. 1832-1840, 2014.

[3] F. Jin, H. Wan, Z. Huang, and M. Gu, "PMSM vector control based on fuzzy PID controller," Journal of Physics: Conference Series, vol. 1617, Article ID 012016, 2020.

[4] Y. Guo, C. Zhang, Z. Wang, and L. Huang, "Study on the method of fuzzy PID control for DC/DC converter," in Proceedings of the 2010 International Conference on Information, Networking and Automation (ICINA), pp. V1V329-V1-332, Kunming, China, October 2010.

[5] H. Zhang, X. Tong, and J. Yin, "Optimal triple-phase-shift controller design of isolated bidirectional DC-DC converter based on ant colony algorithm and BP neural network," in Proceedings of the IECON 2017 - 43rd Annual Conference of the IEEE Industrial Electronics Society, pp. 8802-8807, Beijing, China, November 2017.

[6] M. M. Nishat, F. Faisal, A. J. Evan, M. Rahaman, S. Sifat, and H. M. Fazle Rabbi, "Development of genetic algorithm (ga) based optimized PID controller for stability analysis of DCDC buck converter," Journal of Power and Energy Engineering, vol. 8, no. 9, Article ID 89002, 2020.

[7] Y. Chen, S. Liu, C. Xiong, Y. Zhu, and J. Wang, "Research on UAV flight tracking control based on genetic algorithm optimization and improved bp neural network pid control," in Proceedings of the 2019 Chinese Automation Congress (CAC), pp. 726-731, Hangzhou, China, September 2019.

[8] S. Ab-Ghani, H. Daniyal, N. H. Ramlan et al., "Online PSOtuned phase shift angle controller for dual active bridge DC-DC converter," SN Applied Sciences, vol. 2, no. 1, p. 73, 2020.

[9] S. Xu and Y. Jiang, "Research on trajectory tracking method of redundant manipulator based on PSO algorithm optimization," Computer Modeling in Engineering and Sciences, vol. 125, no. 1, pp. 401-415, 2020.

[10] D. Liu, Y. Wang, F. Deng, and Z. Chen, "Triple-phase-shift control strategy for full-bridge three-level (FBTL) DC/DC converter," in Proceedings of the 2018 IEEE Energy Conversion Congress and Exposition (ECCE), pp. 175-181, Portland, OR, USA, September 2018.

[11] A. K. Das and B. G. Fernandes, "Fully ZVS, minimum RMS current operation of isolated dual active bridge DC-DC converter employing dual phase-shift control," in Proceedings of the 2019 21st European Conference on Power Electronics and Applications (EPE '19 ECCE Europe), pp. 1-10, Genova, Italy, September 2019.

[12] S. Bal, D. B. Yelaverthi, A. K. Rathore, and D. Srinivasan, "Improved modulation strategy using dual phase shift modulation for active commutated current-fed dual active bridge," IEEE Transactions on Power Electronics, vol. 33, no. 9, pp. 7359-7375, 2018.

[13] Y. Su, X. Ge, D. Xie, and K. Wang, "An active disturbance rejection control-based voltage control strategy of singlephase cascaded H-bridge rectifiers," IEEE Transactions on Industry Applications, vol. 56, no. 5, pp. 5182-5193, 2020.

[14] H. He, T. Si, L. Sun, B. Liu, and Z. Li, "Linear active disturbance rejection control for three-phase voltage-source PWM rectifier," IEEE Access, vol. 8, pp. 45050-45060, 2020.

[15] M. Saleem, K.-Y. Choi, and R.-Y. Kim, "Resonance damping for an LCL filter type grid-connected inverter with active disturbance rejection control under grid impedance uncertainty," International Journal of Electrical Power \& Energy Systems, vol. 109, pp. 444-454, 2019.

[16] S. Zhong, Y. Huang, and L. Guo, "VA parameter formula connecting PID and ADRC," Science China Information Sciences, vol. 63, no. 9, pp. 1-13, 2020.

[17] Z. Z. Zeng and Z.-Y Chen, "On control theory of PID and auto-coupling PID," Control Theory and Applications, vol. 1$14,2020$.

[18] Z.-Z. Zeng and W.-J. Liu, "Self-coupling PID controllers[J/ OL]," Acta Automatica Sinica, vol. 1-20, 2020.

[19] W. Liu, Q. Zhao, D. Wang et al., "Secondary-side phaseshifted full-bridge converter with reset winding," IET Power Electronics, vol. 13, no. 11, pp. 2252-2259, 2020.

[20] J.-Q. Han, Active Disturbance Rejection Control Tech-Nology, p. XI, National Defense Industry Press, Beijing, China, 2009.

[21] F.-Q. Wang, Z.-Z. Zeng, T. Cheng et al., "Auto-coupling PID control method for strict feedback nonlinear uncertain systems," Control Engineering, vol. 1-8, 2020. 
[22] J. Saeed and A. Hasan, "Unit prediction horizon binary search-based model predictive control of full-bridge DC-DC converter," IEEE Transactions on Control Systems Technology, vol. 26, no. 2, pp. 463-474, 2018.

[23] W. Xiao, L. Lei, Q. Chen, L. Zhang, and S. Quan, "Sliding mode control of a phase shifted full bridge DC/DC converter," in Proceedings of the 2017 32nd Youth Academic Annual Conference of Chinese Association of Automation (YAC), pp. 138-142, Hefei, China, May 2017. 